\title{
PRODUKTIVITAS DAN KUALITAS GETAH PINUS PEHUTANI KELAS UMUR VII DI KESATUAN PENGELOLAAN HUTAN JEMBER
}

\author{
Productivity and Quality of Perhutani Pine Resin in Age Class (KU) Vii from Forest \\ Management Unit Jember
}

\author{
Dias Evayanti , Febriana Tri Wulandari, Dwi Sukma Rini \\ Program Studi Kehutanan, Universitas Mataram \\ Jalan Majapahit No 62, Mataram, NTB \\ "Email : diasevayanti@gmail.com
}

\begin{abstract}
The pine resin tapping have done by Perhutani on pine stand at age $11^{\text {th }}$ (age class iii) to $34^{\text {th }}$ (age class vii), whilst pine resin productivity at the end of age period (age class vii) undiscovered. The aims of this study are to determine the productivity of pine resin, the influence of the diameter class to productivity of pine resin, the value of the yield and a lot of quality pine resin resulting in age class VII in Perum Perhutani Regional Division of East Java KPH Jember. The method used in this study was the experimental method by using a completely randomized design in which the treatment used is class $D 1=26-30 \mathrm{~cm}$, class $D 2=31-35 \mathrm{~cm}$, class $D 3=$ $36-40 \mathrm{~cm}$ and class $D 4=>40 \mathrm{~cm}$. Data analysis used is the analysis of variance ANOVA at 5\% level and continued with LSD. The results showed that the productivity of Perhutani pine resin KU VII from KPH Jember ranging between 3.17 to $16.04 \mathrm{~g} /$ quaree/day, and $8.42 \mathrm{~g} /$ quaree/day in average. The diameter classes affect the productivity of pine resin. The resulting yield value at KU VII ranged from $89.6 \%$ to $95 \%$, with an overall average recovery rate is $91.4 \%$ and the resulting quality of pine resin included in the Super Premium quality.
\end{abstract}

Keywords: Productivity, yield, quality, pine resin.

\section{ABSTRAK}

Penyadapan getah pinus dilakukan oleh Perum Perhutani pada tegakan umur 11 tahun (kelas umur III) sampai umur 34 tahun (kelas umur VII), sementara produktivitas getah pinus pada akhir daur (KU VII) belum banyak diketahui.Tujuan penelitian ini adalah mengetahui produktivitas getah pinus, pengaruh kelas diameter terhadap produktivitas getah pinus, nilai rendemen dan kualitas getah pinus Perhutani kelas umur VII yang berasal dari KPH Jember. Metode yang digunakan dalam penelitian ini adalah metode eksperimen dengan menggunakan Rancangan Acak Lengkap dimana perlakuan yang digunakan yaitu kelas $D 1=26-30 \mathrm{~cm}$, kelas $\mathrm{D} 2=31-35 \mathrm{~cm}$, kelas D3 $=36-40 \mathrm{~cm}$ dan kelas $\mathrm{D} 4=>40 \mathrm{~cm}$. Analisis data dilakukan dengan menggunakan analisis sidik ragam anova pada taraf $5 \%$ dan dilanjutkan dengan uji BNT. Hasil penelitianmenunjukkan bahwa produktivitas getah pinus berkisar antara 3,17 sampai 16,04 g/koakan/hari dengan rata-rata sebesar 8,42 $\mathrm{g} /$ koakan/hari. Faktor kelas diameter berpengaruh terhadap produktivitas getah pinus. Nilai rendemen berkisar antara $89,6 \%$ sampai $95 \%$, dengan rata-rata rendemen keseluruhan yaitu $91,4 \%$ dan kualitas getah pinus yang dihasilkan 
termasuk dalam mutu Super Premium.

Kata kunci : Produktivitas, Rendemen, Kualitas, Getah Pinus

\section{PENDAHULUAN}

Getah pinus merupakan salah satu jenis hasil hutan bukan kayu yang dihasilkan oleh saluran resin dalam kayu gubal Pinus merkusii. Jenis yang banyak dikembangkan adalah jenis Pinus merkusii Jungh et de Vriese yang tumbuh secara alami di daerah Aceh dan Sumatra Utara. Pohon pinus sesuai dikembangkan di daerah dengan ketinggian 200-1500 mdpl. Awalnya jenis ini dikembangkan di daerah Lembang dan Bali pada tahun 1916 (Miftahul, 2007 cit. Silitonga, 1983), dan menyebar ke daerah Jawa yang dikelola oleh Perum. Perhutani. Tegakan Pinus dapat dijumpai di hampir seluruh dataran tinggi pulau Jawa, kecuali di bagian utara pulau Jawa yang merupakan tempat tumbuh tanaman Jati. Pohon pinus selain dimanfaatkan kayunya untuk dijadikan bahan baku pembuatan kertas, furniture, batang korek api, hiasan dinding dan peralatan rumah tangga, juga disadap getahnya sebagai bahan baku gondorukem dan terpentin.

Gondorukem digunakan sebagai campuran bahan batik tulis dan cetak, disamping itu dapat diolah lagi untuk campuran bahan-bahan sabun, cat dan vernis. Sedangkan terpentin digunakan sebagai bahan baku maupun campuran dalam industri minyak, cat, parfume, deterjen, insektisida, obat-obatan, plastik dan karet. Saat ini produksi gondorukem dan terpentin andalan Perum Perhutani menempati urutan ketiga dunia setelah China dan Brazil (Perhutani, 2016). Permintaan gondorukem dan terpentin di pasar internasional di tahun-tahun mendatang diyakini meningkat, disebabkan penggunaan gondorukem yang semakin banyak jenisnya terutama pasar Eropa dan India.

Penyadapan getah pinus oleh Perum Perhutani dilakukan pada umur 11 tahun (kelas umur III) sampai umur 34 tahun (kelas umur VII). Selanjutnya pohon pinus akan ditebang dan dimanfaatkan kayunya. Berdasarkan hasil penelitian Sukarno, Hardiyanto \& Marsoem (2012) di RPH Oro-oro Ombo, BKPH Pujon, KPH Malang diketahui bahwa produksi getah pinus meningkat dari kelas umur III $(36,5 \mathrm{~g} / 2$ lubang/1 hari) ke kelas umur IV (62,9 g/2 lubang/1 hari), kemudian menurun pada kelas umur V (24,61 g/2 lubang/1 hari) dan sedikit meningkat pada kelas umur VI (38,3 g/2 lubang/1 hari).

Produktivitas getah pinus pada akhir daur (KU VII) belum banyak diketahui. Disisi lain, berdasarkan hasil survei lapangan yang telah dilakukan peneliti di KPH Jember, terdapat perbedaan diameter pada tegakan Pinus KU VII, dengan kata lain dalam satu kelas umur yang sama terdapat kecepatan pertumbuhan yang berbeda. Penelitian ini bertujuan untuk mengetahui produktivitas getah pinus Perhutani KU VII, pengaruh kelas diameter terhadap produktivitas getah pinus Perhutani KU VII, rendemen dan kualitas getah pinus Perhutani yang dihasilkan pada KU VII dengan metode koakan di KPH Jember. 


\section{METODE}

Penelitian ini dilaksanakan pada bulan Agustus-Januari 2018 dengan rincian waktu sebagai berikut : Penyadapan getah pinus dilakukan selama 2 pekan di petak 1B RPH Garahan, BKPH Sempolan, Perum Perhutani KPH Jember. Perhitungan produktivitas serta nilai rendemen dan uji kualitas getah pinus yang bertempat di TPG I Kuntiran, RPH Garahan, BKPH Sempolan, Perum Perhutani KPH Jember

Alat dan bahan yang digunakan dalam penelitian ini adalah pita ukur, kadukul, talang sadap, wadah penampungan, alat tulis, tally sheet, kalkulator, timbangan analitik, saringan 100 mesh, tongkat pengambil contoh uji, dan ember plastik.Pelaksanaan penelitian meliputi tahap pemilihan pohon pinus, penyadapan getah pinus dan pengujian. Parameter yang diamati adalah produktivitas (gram/koakan/hari), rendemen (\%), dan kualitas getah pinus.

Penelitian ini menggunakan Rancangan Acak Lengkap dimana perlakuan yang digunakan adalah kelas diameter, yaitu: kelas $D 1=26-30 \mathrm{~cm}$, kelas D2 $=31$ $35 \mathrm{~cm}$, kelas $\mathrm{D} 3=36-40 \mathrm{~cm}$ dan kelas $\mathrm{D} 4=>40 \mathrm{~cm}$ sebanyak 20 pohon. Analisis data produktivitas dan rendemen menggunakan Analisis Sidik Ragam (ANOVA) pada taraf nyata $5 \%$ dan di uji lanjut dengan uji BNT (beda Nyata Terkecil) pada taraf nyata $5 \%$, sedangkan untuk pengujian kualitas dianalisis secara deskriptif dengan menginterpretasikan data dalam bentuk angka dan tabulasi.

\section{HASIL dan PEMBAHASAN}

\section{Produktivitas getah pinus}

Penyadapan getah pinus dilakukan pada pohon yang telah mengalami koakan ke-6 pada bulan agustus-september 2017 di petak 1B Perum Perhutani Divisi Regional Jawa Timur KPH Jember dengan luas petak 25,40 ha yang ditanami 6.593 pohon pinus. (Data Perum Perhutani KPH Jember, 2017). Hasil perhitungan produktivitas getah pinus dapat dilihat pada Tabel 1.

Tabel .1. Produktivitas Getah Pinus merkusii (gram/koakan/hari).

Table .1.Productivity of Pine Resin (grams/quaree/day).

\begin{tabular}{|c|c|c|c|c|c|}
\hline \multirow[b]{2}{*}{ Ulangan } & \multicolumn{4}{|c|}{ Kelas Diameter } & \multirow{7}{*}{$\begin{array}{l}\text { Rata- } \\
\text { rata }\end{array}$} \\
\hline & $\mathrm{D} 1$ & $\mathrm{D} 2$ & D3 & D4 & \\
\hline 1 & 3,50 & 3,92 & 12,52 & 10,96 & \\
\hline 2 & 3,17 & 7,72 & 16,04 & 11,62 & \\
\hline 3 & 7,66 & 5,54 & 10,26 & 7,92 & \\
\hline 4 & 5,01 & 6,36 & 12,00 & 11,50 & \\
\hline 5 & 3,96 & 6,67 & 10,36 & 11,72 & \\
\hline $\begin{array}{c}\text { Rata-rata } \\
\text { (gram/koakan/hari) }\end{array}$ & 4,66 & 6,04 & 12,24 & 10,74 & 8,42 \\
\hline
\end{tabular}

Produktivitas penyadapan getah pinus rata-rata sebesar $8,42 \mathrm{~g} / \mathrm{koakan} / \mathrm{hari}$, berkisar antara 3,17 g/koakan/hari sampai 16,04 g/koakan/hari. Hal ini menunjukkan 
bahwa tegakan pinus KU VII di petak 1B Perum Perhutani KPH Jember mampu memproduksi getah pinus secara baik sesuai dengan target yang telah di direncanakan yaitu $8 \mathrm{gram} /$ pohon/hari (Hasil olah data Perum Perhutani KPH Jember bulan November 2017 ). Selain itu, jika dilihat produktivitas getah pinus dalam satu kelas umur menunjukkan perbedaan untuk tiap kelas diameter. Peningkatan produktivitas getah pinus terjadi seiring dengan bertambahnya diameter. Peningkatan produktivitas terjadi dari D1 sampai dengan D3, kemudian terjadi penurunan pada D4 karena sudah mencapai batas maksimal, namun hasilnya tidak berbeda signifikan dengan D3 (Gambar 1). Hasil analisis keragaman menunjukkan bahwa kelas diameter berpengaruh terhadap produktivitas getah yang dihasilkan.

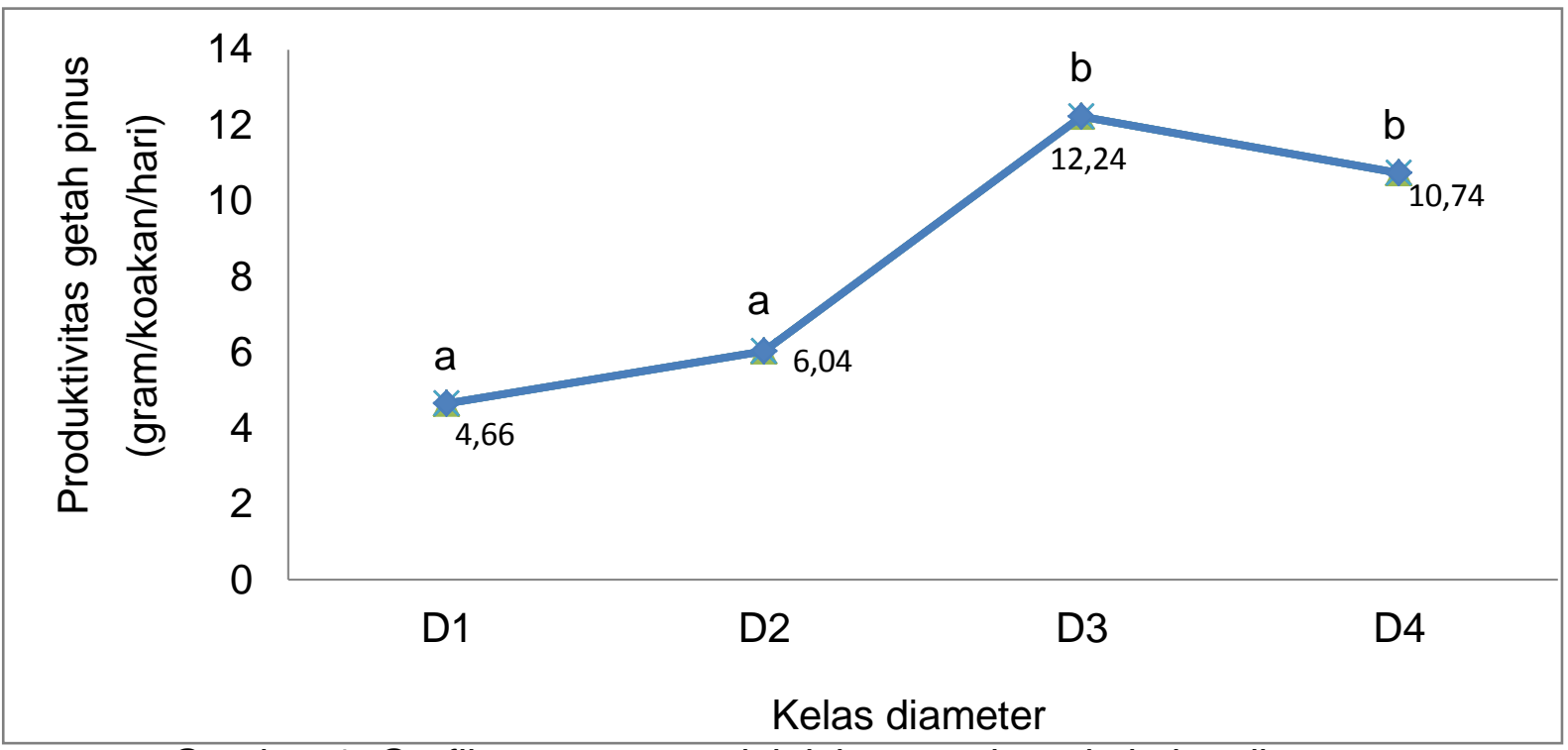

Gambar 1. Grafik rata-rata produktivitas getah pada kelas diameter

Figure 1. Graph of average productivity of sap in diameter class

Penelitian Sulistyono (1995) cit. Sonljana (1990) di BKPH Singaparna KPH Tasikmalaya menunjukkan bahwa semakin besar diameter akan menghasilkan getah pinus lebih banyak dibandingkan diameter kecil. Menurut Wibowo (2006), semakin besar diameter pohon maka produktivitas getah akan semakin meningkat. Hal ini dikarenakan semakin besar diameter, maka volume kayu gubal dalam pohon akan bertambah, dan saluran resin juga akan meningkat. Variasi produktivitas getah pinus juga dapat dilihat pada produktivitas getah pinus di daerah Sukabumi, yaitu berkisar antara sebesar 8,01 g/pohon/hari sampai dengan 13,93 g/pohon/hari (Sudradjat, 2002). Selain itu juga pada penyadapan getah pinus di Hutan Pendidikan Gunung Walat yaitu sebesar $8,57 \mathrm{~g} /$ pohon/hari dengan rata-rata untuk masingmasing blok kerja Cikatomas, Tangkalak dan Cimenyan berturut-turut yaitu 7,75 g/pohon/hari, 8,54 g/pohon/hari dan 9,43 g/pohon/hari ( Wibowo, 2006)

\section{Rendemen Getah Pinus}

Nilai rendemen pada kelas umur VII berkisar antara $89,6 \%$ sampai $95 \%$ (Tabel 2). Dengan rata-rata rendemen keseluruhan yaitu 91,4\%. Rendemen getah pinus yang dihitung merupakan total produksi getah yang diperoleh setelah dibersihkan dari kotoran-kotoran yang menyertai getah dalam tempat penampungan getah. Tinggi rendahnya rendemen dapat dipengeruhi oleh beberapa faktor, seperti 
adanya daun, ranting, bunga dan air yang jatuh kedalam penampungan getah, begitu juga dengan faktor cuaca dan iklim saat penyadapan getah. Saat curah hujan tinggi air akan masuk kedalam tempat penampungan getah karena tidak adanya penutup yang melindungi getah. Menurut pengamatan dilapangan nilai rendemen dapat mencerminkan kualitas getah pinus yang dihasilkan, semakin tinggi nilai rendemen maka kualitas getah pinus yang dihasilkan semakin baik dikarenakan adanya faktor kadar kotoran dan air yang sedikit, begitu juga sebaliknya semakin rendah nilai rendemen maka kualitas getah pinus yang dihasilkan semakin buruk.

Tabel 2. Rendemen getah pinus

Table 2. Yield of Pine Resin

\begin{tabular}{ll}
\hline Kelas Diameter & Rendemen \\
\hline D1 & $89,6 \%$ \\
D2 & $89,9 \%$ \\
D3 & $90,8 \%$ \\
D4 & $95,0 \%$ \\
\hline Rata-rata & $91,4 \%$ \\
\hline
\end{tabular}

\section{Kualitas getah pinus}

Kualitas getah pinus dinilai dengan melihat hasil uji karakteristik getah berupa warna, kadar air (KA) dan kadar kotoran (KK) getah. Warna sangat dipengaruhi oleh jumlah kadar air dan kadar kotoran yang tercampur pada saat proses penyadapan getah pinus. Kadar air merupakan jumlah air yang terdapat dalam getah yang terikat secara emulsi maupun yang terlarut dalam getah (SNI 7837:2016). Semakin rendah nilai kadar air pada getah pinus maka mutu getah pinus juga semakin baik. Sementara kadar kotoran merupakan benda lain yang tercampur di dalam getah yang tidak larut dalam terpentin atau pelarut organik lainnya yang dapat melarutkan getah (SNI 7837:2016). Semakin sedikit kadar kotoran yang terdapat pada getah pinus maka mutu getah pinus juga semakin baik.

Dari hasil penelitian didapatkan getah pinus berwarna putih, $K A+K K$ mencapai $3,37 \%$ atau $<5 \%$, sehingga masuk dalam mutu super premium. Mutu super premium merupakan mutu paling baik dalam pengujian getah pinus dan sesuai dengan standar mutu pinus SNI 7837:2016 (Tabel 3).

Tabel 3. Hasil pengujian kualitas getah pinus

Table 3. Results of testing the quality of pine resin

\begin{tabular}{|c|c|c|c|c|c|c|}
\hline \multirow[b]{2}{*}{ No } & \multirow[b]{2}{*}{ Karakteristik } & \multirow{2}{*}{$\begin{array}{c}\text { Hasil } \\
\text { penelitian }\end{array}$} & \multicolumn{4}{|c|}{ Standar SNI } \\
\hline & & & $\begin{array}{c}\text { Super } \\
\text { premium }\end{array}$ & Premium & Mutu I & Mutu II \\
\hline 1 & Warna & Putih & Putih & Putih & Putih & $\begin{array}{c}\text { Putih } \\
\text { sampai } \\
\text { keruh } \\
\text { kecoklat- } \\
\text { coklatan }\end{array}$ \\
\hline 2 & $\begin{array}{l}\mathrm{KA}+\mathrm{KK} \\
(\%)\end{array}$ & $\begin{array}{r}1,5+1,87 \\
=3,37\end{array}$ & $\leq 5$ & $>5-10$ & $>10-\leq 14$ & $>14-\leq 18$ \\
\hline
\end{tabular}

Keterangan: $\mathrm{KA}=$ Kadar Air, $\mathrm{KK}=$ Kadar Kotoran 
Pada saat penelitian, curah hujan di tempat penelitian tergolong rendah, sehingga kadar air getah pinus yang diperoleh rendah. Menurut Dahlian dan Hartoyo (1997), ada beberapa faktor yang dapat mempengaruhi kualitas getah pinus antara lain faktor internal pohon, faktor eksternal (kondisi lingkungan), faktor perlakuan manusia dan faktor genetik. Sementara itu, kadar kotoran tergolong tinggi dapat disebabkan tempat penampungan getah yang digunakan adalah tempurung kelapa, sehingga memungkinkan serasah atau daun pohon pinus yang jatuh masuk ke dalam tempat penampungan. Selain itu, tingginya kadar kotoran juga dapat disebabkan adanya serangga yang terperangkap pada saluran getah dan tempat penampungan getah, karena aroma getah pinus menarik perhatian serangga.

\section{KESIMPULAN}

Berdasarkan hasil peyadapan getah pinus dan pengujian parameterparameter yang telah diamati, dapat di ambil kesimpulan sebagai berikut:

1. Produktivitas getah pinus Perhutani KU VII di KPH Jember berkisar antara 3,17 $\mathrm{g} / \mathrm{koakan} /$ hari sampai $16,04 \mathrm{~g} / \mathrm{koakan} / \mathrm{hari}$.

2. Kelas diameter berpengaruh terhadap produktivitas getah pinus yang dihasilkan pada taraf $5 \%$.

3. Nilai rendemen yang dihasilkan pada KU VII berkisar antara $89,6 \%$ sampai $95 \%$, dengan rata-rata rendemen keseluruhan yaitu $91,4 \%$.

4. Kualitas getah pinus Perhutani KU VII di KPH Jember termasuk dalam mutu Super Premium, sehingga dapat dipertimbangkan untuk dilakukan penyadapan sampai akhir daur (KU VII).

\section{DAFTAR PUSTAKA}

Badan Standarisasi Nasional. 2016. SNI 7837:2016 Getah Pinus. Jakarta: Badan Standarisasi Nasional.

Dahlian, E. \& Hartoyo. 1997. Komponen Kimia Terpentin dari Getah Tusam (Pinus merkusii) Asal Kalimantan Barat. Info Hasil Hutan. Badan Pengembangan dan Penelitian Kehutanan. Bogor. 4(1):38-39

Herjanto, E. 2007. Manajemen Operasi. Jakarta: Grasindo.

Miftahul, U, M. 2007. Pengaruh Kelas Umur dan Jenis Stimulansia serta Analisis Biaya Pendapatan pada Penyadapan Getah Pinus (Pinus merkusii Jungh Et De Vriese) (Studi Kasus: RPH Ciguha BKPH Cikawung KPH Sukabumi Perum Perhutani Unit III Jawa Barat dan Banten). Skripsi. Fakultas Kehutanan Institut Pertanian Bogor. Bogor.

Perhutani, 2016. Produsen Gumrosin Dan Turpentin Terbesar Ketiga Dunia Adakan Pertemuan Dengan Buyer Internasional Untuk Meningkatkan Pelayanan. Kementrian BUMN. Diakses pada tanggal 13 Maret 2018.

Dari

http://bumn.go.id/perhutani/berita/3237/Perhutani,.Produsen.Gumrosin.Dan.Tur pentin.Terbesar.Ketiga.Dunia.Adakan.Pertemuan.Dengan.Buyer.Internasional.

Untuk.Menin\%20gkatkan.Pelayanan.

Sudrajat. 2002. Pengaruh Diameter Pohon, Umur, Kadar Stimulan dan Persediaan Pemunggutan. Buletin Penelitian Hasil Hutan Vol 20 No 2. 145. 
Sukarno, A., Hardiyanto, E, B., \& Marsoem, S, N. 2012. Pengaruh Perbedaan Kelas Umur Terhadap Produktivitas Getah Pinus merkusii Jungh et de Vriese Ras Lahan Jawa Melalui Penyadapan Getah Metode Bor. J-PAL Vol 3 No 1.29-31.

Sulistyono. 1995. Pengaruh Tinggi Tempat terhadap Produksi Getah Pinus (Pinus merkusii Jungh Et De Vriese) di KPH Probolinggo Perum Perhutani Unit II Jawa Timur. Skripsi. Fakultas Kehutanan Institut Pertanian Bogor. Bogor.

Wibowo, P. 2006. Produktivitas Getah Pinus merkusii Jungh et de Vriese dengan Sistem Koakan di Hutan Pendidikan Gunung Walat Kabupaten Sukabumi Jawa Barat. Skripsi. Fakultas Kehutanan Institut Pertanian Bogor. Bogor. 